\title{
Degree of saturation effect on the grout-soil interface shear strength of soil nailing
}

\author{
Qiong Wang ${ }^{1}$, Xinyu $\mathrm{Ye}^{1}$, Shanyong Wang ${ }^{\mathrm{a}, 1}$, Scott William Sloan ${ }^{1}$, Daichao Sheng ${ }^{1}$ \\ ${ }^{1} A R C$ Centre of Excellence for Geotechnical Science and Engineering, The University of Newcastle, Callaghan, 2308 NSW, Australia
}

\begin{abstract}
In the grouted soil nailing system, the bonding strength of cement grout-soil interface offers the required resistance to maintain the stability of whole structure. In practice, soil nailing applications are often placed at unsaturated conditions, such as soil slopes, shallow foundations, retaining walls and pavement structures. In these cases, the water content in the soil nail zone may increase or decrease due to rain water or dry weather, and even cannot become saturated during their design service life. In this study, the effect of water content (degree of saturation) on the shear strength of interface between cement grout and sand are experimentally investigated by means of direct shear test. Meanwhile the water retention curve was determined and interface microstructure was observed. Experimental results show that the shear strength of interface changes non-monotonously with degree of saturation when the interface was prepared, due to the non-monotonousness of the cohesiveness between soil particles. The less the cohesiveness between sand particles, the more grout was observed been penetrated into the voids, and thus the larger the interface shear stress.
\end{abstract}

\section{Introduction}

The fundamental mechanism of grouted soil nail is the development of tensile forces in the passive zone. The tensile forces generated are transferred to the soil through friction mobilized at the grout/soil interface, and tends to restrain the reinforcements from pull-out [1, 2]. Therefore, the pull-out shear resistance between the grout and the surrounding soils is of primary importance for design and safety assessment of soil nailing system [3].

Traditionally, the design of soil nail is assumed in the conditions of saturated soils, where the effect of matric suction or the negative pore water pressure in the unsaturated zone is neglected. However, soil nailing applications are often placed at unsaturated conditions in the practice, such as soil slopes, shallow foundations, retaining walls and pavement structures. In these cases, the water content in the soil nail zone may increase or decrease due to rain water or dry weather, and even cannot become saturated during their design service life. The soil mechanic behaviour is significantly influenced by the water content changes (degree of saturation which in turn leads to different grouting behaviour and interface performance.

In this study, the effect of soils degree of saturation (water content) when the grout was injected, on the interface shear stress of cement grout-sand was investigated by means of direct shear test. Soil water retention curve was accordingly determined as it demonstrates the unsaturated soil behaviour. While the cement-sand interface obtained at different water content

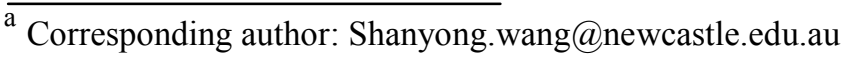

was observed by using microscope, which helps to explain the differences in shear stress.

\section{Materials and Methods}

\subsection{Materials}

The soil tested is silica sand obtained from Stockton Beach, Newcastle, Australia. It consists $98.82 \%$ of quartz, $0.8 \%$ of rock fragments, $0.21 \%$ of Zircon, $0.11 \%$ of Ilmenite and $0.06 \%$ of Rutile [4]. With a specific gravity of $2.67 \mathrm{Mg} / \mathrm{m}^{3}$, the maximum and minimum densities are $1.71 \mathrm{Mg} / \mathrm{m}^{3}$ and $1.46 \mathrm{Mg} / \mathrm{m}^{3}$, respectively. The grain size distribution curve determined by dry sieving is shown in Figure 1, which is characterized as by a uniformity coefficient $\mathrm{C}_{\mathrm{u}}$ of 3.56 and a D50 close to $0.9 \mathrm{~mm}$.

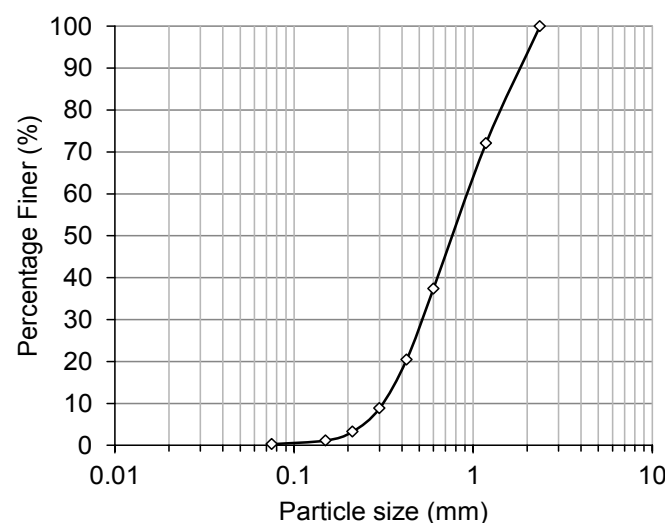

Figure 1 Particle size distribution of Stockton sand 
The cement grout used was in a water cement ratio $(w / c)$ of 0.5 . It was prepared by locally available Portland cement. The properties of the cement grout material are listed in Table 1. It has an initial setting time of 1.5-3 hours, and final setting time of 2.5-4 hours. The soundness is $1.0 \mathrm{~mm}$ and the specific gravity is 3.14 .

Table 1. Fundamental properties of Portland cement

\begin{tabular}{|c|c|}
\hline Properties & Values \\
\hline Initial setting time & $1.5-3$ hours \\
\hline Final setting time & $2.5-4$ hours \\
\hline Soundness & $1.0 \mathrm{~mm}$ \\
\hline Fineness & $330-410 \mathrm{~m}^{2} / \mathrm{kg}$ \\
\hline Specific gravity & 3.14 \\
\hline
\end{tabular}

\subsection{Experimental Methods}

\subsubsection{Samples preparation}

Sand at certain water content was firstly prepared by water spraying method from oven dried sand. A given quantity of the wet sand was then placed in the sample mould (for water retention test) or shear box (for shear test) and compacted to a desired void ratio of 0.80 (classified as loose sand). The sample with desired degree of saturation was thus obtained.

\subsubsection{Water retention curve of the compacted sand}

To obtain the water retention curve (WRC) of the compacted sand in this study, a tensiometer with measurement range of -100 to $100 \mathrm{kPa}( \pm 1.5 \%$ accuracy of the full range) was employed (see Figure 2a). Several samples at different water content (corresponding to different degree of saturation) were compacted in the testing moulds to the same void ratio of 0.80 (Figure $2 b$ ). After compaction, a special tube with the same diameter of the tensiometer probe ( $6 \mathrm{~mm}$ in diameter) was used to drill a hole for the tensiometer installation, the surface of the sample was covered to avoid the evaporation. The reading of the tensiometer was continually monitored, and the value at the stability was recorded as the soil suction.

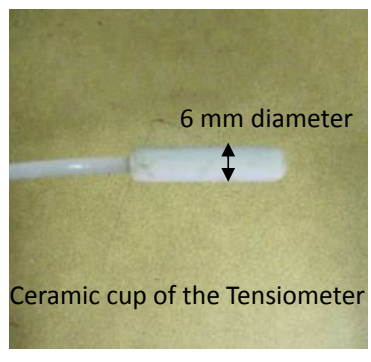

(a) Tensiometer probe

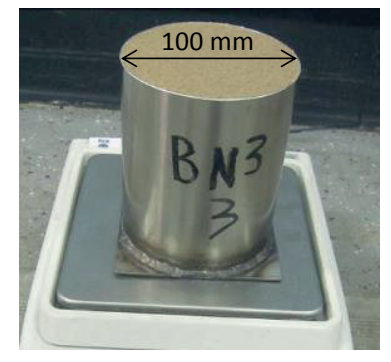

(b) Soil mould
Figure 2 Instruments used for the WRC determination

\subsubsection{Direct shear test at the interface}

The interface shear stress between the unsaturated sand and cement grout was studied by using a conventional direct shear box apparatus shown in Figure 3. Both upper and bottom shear box is in dimension of $\varnothing 63 \mathrm{~mm}$ and 20 $\mathrm{mm}$ high.

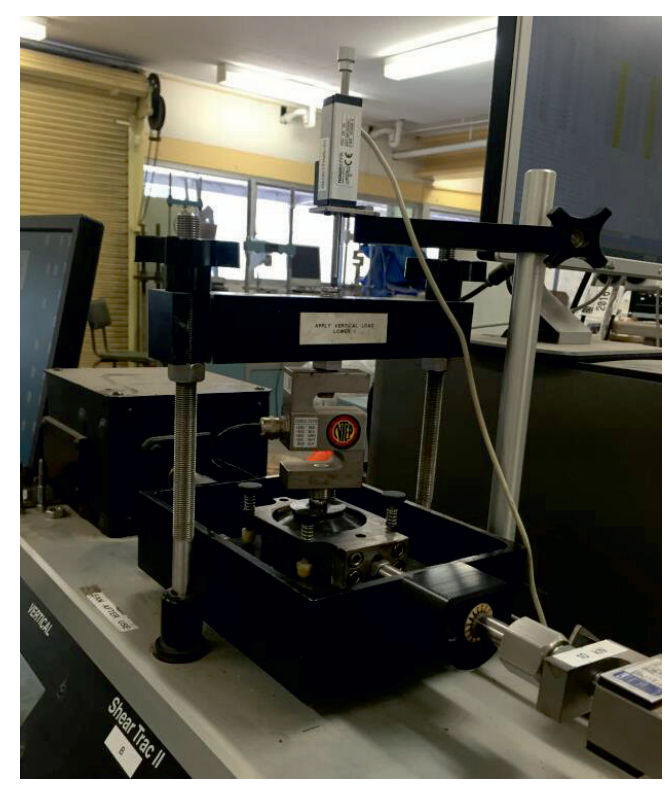

Figure 3 Photo of the direct shear box apparatus used

For the preparation of the cement grout-sand interface, the sand sample at certain water content was first compacted in the interface sealed shear box (Figure 4a) to the void ratio of $0.80 \mathrm{Mg} / \mathrm{m}^{3}$. Considering the producing of a cemented sand layer at the interface and the compaction of soil due to grouting pressure (Figure c), the height of the soil was designed $1 \mathrm{~mm}$ higher than the bottom shear box (see Figure $4 a$ ), as the shear plane will be most possible on the surface of this layer and sand. This value $(1 \mathrm{~mm})$ was chosen based on several preparation tests.

The cement grout with $w / c$ ratio of 0.5 was then obtained by mixing certain mass of water and cement powder. After mixed thoroughly using a blender, the grout was poured on the top surface of the compacted sand sample. A piston was the then put on the top to apply the vertical pressure by mechanical loading frame, which simulates the grouting pressure. The void between piston and the box wall was sealed by a special added oring to avoid the leakage of grout from the top. The same vertical pressure of $100 \mathrm{kPa}$ was applied for all tests performed. Compaction, bleeding and penetration will be occurred at the interface of the grout and sand during this process, producing a cemented grout layer (Figure 4b). The cement grout was allowed to harden for 24 hours, during which the vertical pressure was kept constant.

Afterwards, the vertical pressure was released and the bolts used to fix the upper and bottom box was removed, a space was then created at the interface. Direct shear test was conducted under vertical pressure of $50 \mathrm{kPa}$ at a shear speed of $1.00 \mathrm{~mm} / \mathrm{min}$. Corresponding strength value was measured automatically by the machine, allows 
the plotting of the displacement-shear strength curve. Totally eleven tests were performed on sand samples at different initial water content (degree of saturation) ranges from $2 \%$ to $22 \%$, corresponding to the degree of saturation of $6 \%$ to $73 \%$.

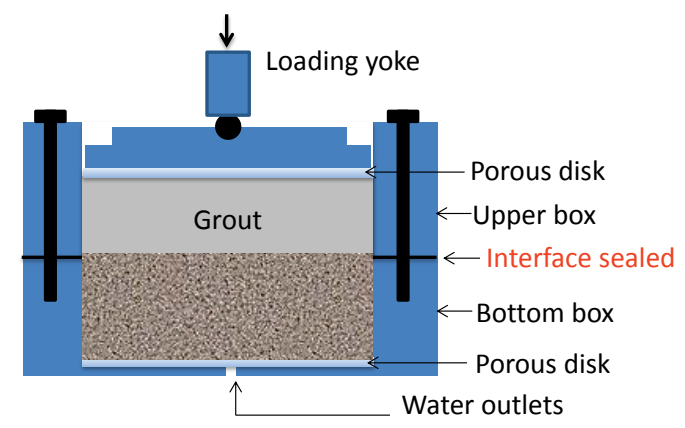

(a) Interface preparation process

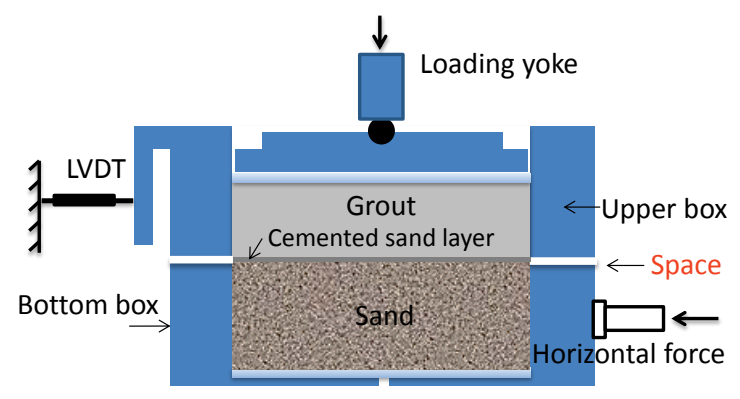

(b) Shear process

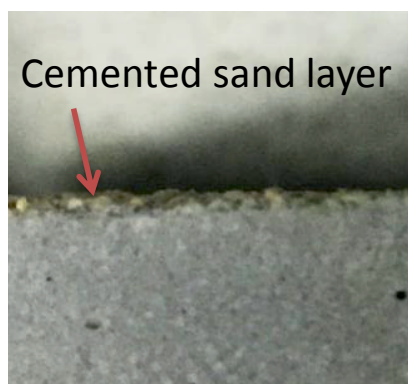

(c) Cemented sand layer

Figure 4 Schematic view of the experimental process

\subsubsection{Microstructure observation of the interface}

After the conduction of the interface shear test, the cemented layer of the interface obtained at different initial degree of saturation was observed by using a $200 \times$ magnification microscope. The penetration of cement grout into the sand voids could be visually investigated, which allows the explanation of the effect of degree of saturation on the interface shear stress.

\section{Results and discussion}

\subsection{Water retention curve}

The suction of the sand sample (void ratio of 0.80 ) at different water content (i.e. different degree of saturation) was measured by using a tensiometer and plotted with water content in Figure 5. An air entry value of $3.1 \mathrm{kPa}$ could be estimated from the curve, which corresponds to water content of $26 \%$; while the residual water content was at around $2 \%$. It can be observed that from the water content of $2 \%$, which is located at the residual zone (Figure 6a), the water amount is very small (i.e. the water menisci is small) and resulting in a small cohesiveness between sand particles. The cohesion increases with the increase of water content (water menisci) and then entries into the transition zone (Figure 6b). The water content in the soil increases significantly with the decreasing suction, where the water menisci area in contact with the sand particles increases as saturation continues, thus leading to an increase in the cohesiveness. However, after a certain value of water content, where water phase are connected with air phase being isolated (Figure 6c), the surface tension force of the water menisci breaks, therefore the cohesiveness between sand particles became less and less until it was disappeared in the boundary effect stage (saturation state in Figure 6d). In the figure, the water contents at which cement-soil interface was prepared are also plotted, showing the positon of the samples on the water retention curve.

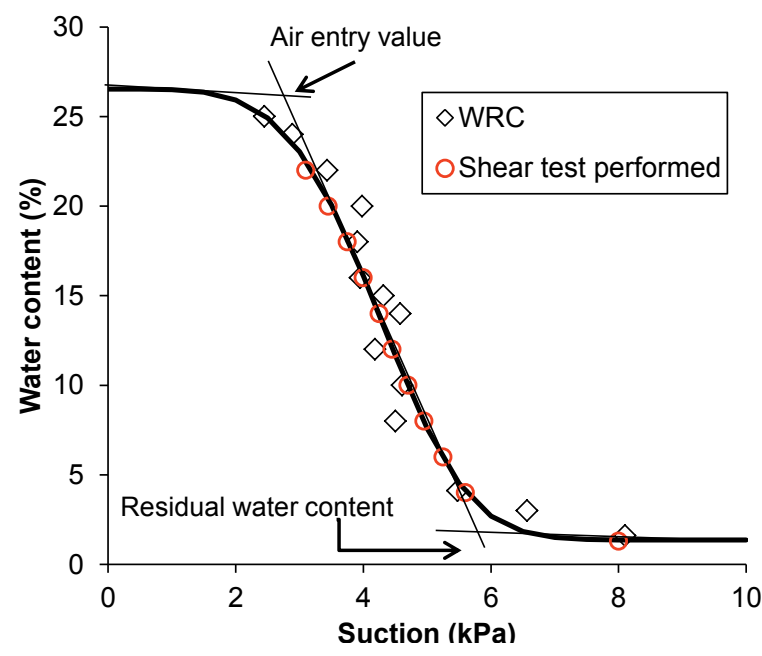

Figure 5 Water retention curve of the compacted sand

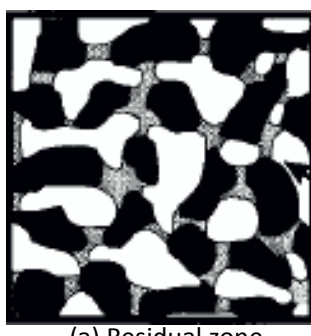

(a) Residual zone

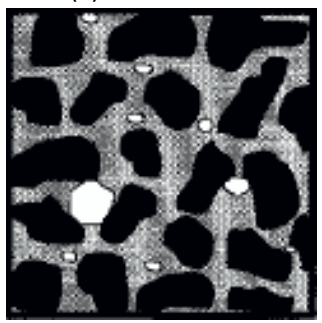

(c) Boundary zone II

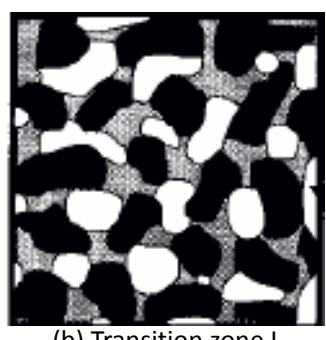

(b) Transition zone

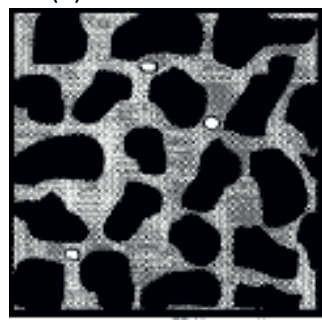

(d) Boundary effect zone
Sand particles

Water

Figure 6 Water areas in different stages of the water retention curve (after Vanapalli et al. 1995) [9] 


\subsection{Interface shear stress}

The shear stress-horizontal displacement curves of the grout-sand interface prepared at different water content (degree of saturations) are showed in Figure 7. All curves show similar trend and shape: the interface shear stress gradually increases with shear displacement until it reaches the maximum shear strength, after which it decreases slightly or remains almost constant. Regarding the effect of water content, it can be seen that the curve for the sample at the lowest water content of $2 \%(6 \%$ of $S_{r}$ ) in this study locates at the top, indicating the largest shear stress at the interface; while the curves for initial water content of $4 \%$ and $22 \%$ followed subsequently. It seems that there is no obvious relationship between water content (degree of saturation) and interface shear stress, as the curves are not ordered with the increase of decrease of water content.

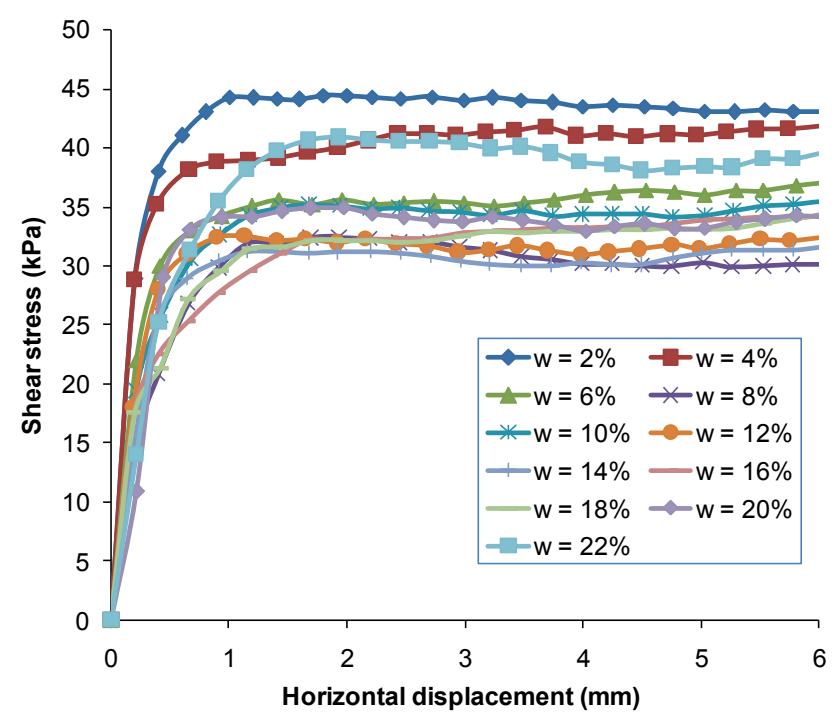

Figure 7 Shear stress Vs. horizontal displacement

To further analysis the increase of degree of saturation on the interface shear strength, the peak shear stress and residual stress were obtained from the curve and plotted versus the water content (degree of saturation) in Figure 8. It can be observed that the changes of interface shear strength with water content increase are not monotonic increase or decrease. Instead, with the water content increase from $2 \%$, both the peak and residual stress decreases up to $6 \%$, followed by an almost constant stage ranged from $6 \%$ to about $18 \%$; afterwards, the shear stress increase with further water content increase. This variation trend is similar to the relationship between the injected grout volume and the degree of saturation (water content) for the same soil at the same void ratio [5]. These two phenomena are actually followed the same mechanism due to the preparation of the interface in this study was also intend to simulate the pressure grouting process. According to the previous study [6,7], the complicated mechanism of soil grout interaction during pressure injection involves the compaction of soil by grouting pressure as well as penetration and bleeding of the grout, which are affected by the mechanic behaviour of soil, i.e. bear capacity (compressibility) and shear stress (cohesiveness).

During injection, the pressurized grout may penetrate into the soil voids considerably, enhancing the bond strength and interface roughness between the grout part and surrounding soil. Therefore the shear stress of interface in Figure 8 is attributed to different bond strength and interface roughness obtained at different water content (degree of saturation). It can be seen from test positions in the water retention curve (Figure 6), due to the increase of sand cohesion consequently bearing capacity with increase of water content from 2\% [8] (Figure 6a), less and less grout could be penetrated into the sand and the interface shear stress decreased. However, up to a certain water content until the surface tension force of the water film suspended between the pores breaks (Figure 6c), the subsequent increase of water content (decrease of suction) may induce a reduction in the cohesiveness, thus an increment of penetration leading to an increase of interface shear stress.

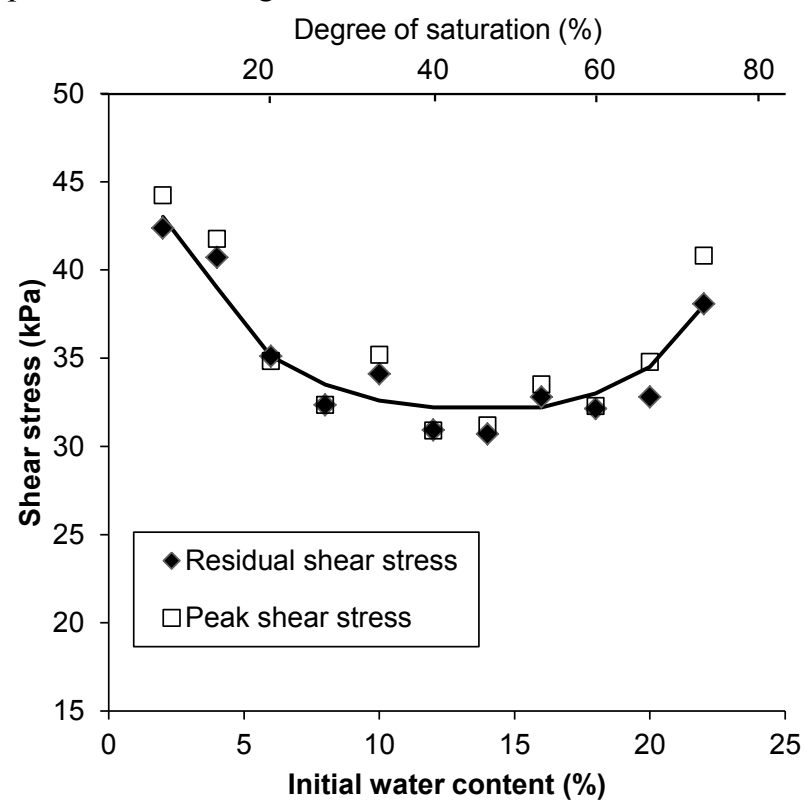

Figure 8 Shear stress Vs. initial water content (degree of saturation) of sand

\subsection{Microstructure observation}

The microstructures of the grout-sand interface obtained at different initial degree of saturation are presented in Figure 9. From the photo, it is clearly that the voids between sand particles at the degree of saturation of $6 \%$ (Figure 9a) are almost filled by the hardened grout; as the degree of saturation increase up to $45 \%$, obvious less and less cement is filled between sand particles: at the degree of saturation of $20 \%$, around half of voids is filled (Figure 9b), while for the $40 \%$ and $45 \%$ degree of saturation, there are just a few cement was attached between the contact surface of sand particle (Figure 9c and 9d). Thereafter, the subsequent increase of degree of saturation to $60 \%$ and $70 \%$ does not reduce the cement filled voids, instead, more and more voids between sand particles are filled by the hardened grout. The microstructure variation with initial degree of saturation 
is in agreement with the changes of interface shear stress (shown in Figure 8) as well as the corresponding explanation made on from water retention curve (Figure 6 ). The less the cohesiveness between sand particles, the more grout could be penetrated into the voids, and thus the larger the interface shear stress.

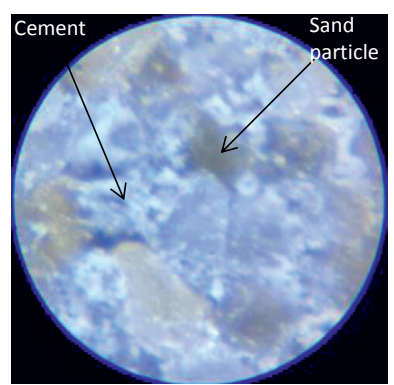

(a) $S_{r}=5 \%$

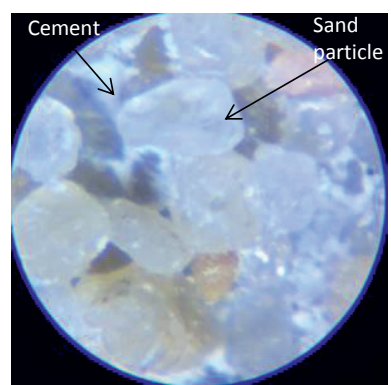

(a) $S_{r}=35 \%$

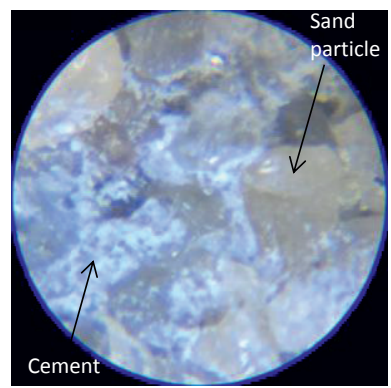

(a) $S_{r}=60 \%$

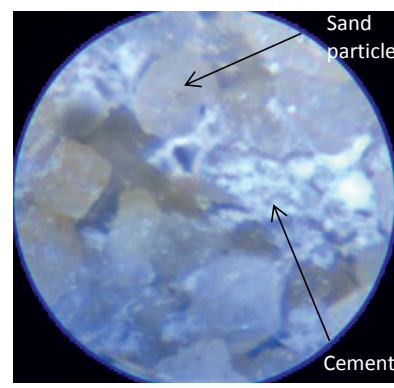

(b) $S_{r}=20 \%$

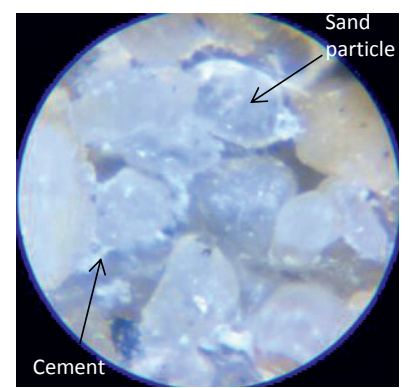

(b) $S_{r}=45 \%$

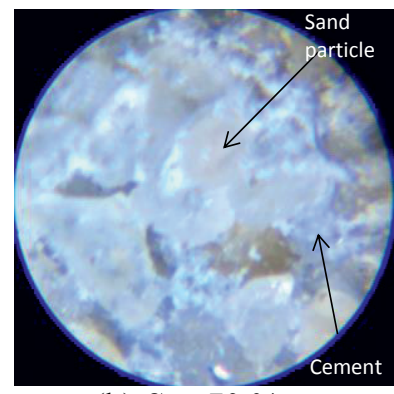

(b) $S_{r}=70 \%$
Figure 9 Microscope photos of the interface

\section{Conclusion}

In order to investigate the effect of degree of saturation on the interface shear stress between the grout and soil in soil nailing, a series of direct shear tests were conducted on interface prepared at different soils degree of saturation/water content. Meanwhile, the soil water retention curve and interface microstructure were also investigated.

With the degree of saturation (water content) increase both the peak and residual shear stress at the interface decreases, followed by an almost constant stage; afterwards, the shear stress increase with further water content increase.

Interface shear stress changes are in agreement with the different bond strength and interface roughness obtained at different degree of saturation (water content): the less the cohesiveness between sand particles, the more grout is observed to ben penetrated into the voids, and thus the larger the interface shear stress.

\section{References}

1. F. Schlosser, Behaviour and design of soil nailing. Proceedings of theInternational Symposium on Recent Development in Ground Improvement Techniques, Bangkok: 399-413(1982)

2. A. Guilloux, and F. Schlosser, Soil nailing: practical applications,Proc. Symp. OnRecent Developments in Ground Improvement Techniques, Bangkok, 389-397 (1982)

3. M. A. Hossain, and J. H. Yin, Influence of Grouting Pressure on the Behavior of an Unsaturated Soil-Cement Interface, J. Geotech. Geoenviron. Eng. 138:193-202 (2012)

4. R. Ajalloeian, H.S. Yu, and Allman, M.A., Physical and Mechanical Properties of Stockton Beach Sand, 7th Australia New Zealand Conference on Geomechanics: Geomechanics in a Changing World: Conference Proceedings. Barton, ACT: Institution of Engineers, Australia, 60-65 (1996)

5. Q. Wang. S.Y. Wang, S.W. Sloan, D.C. Sheng, R.Pakzad, Experimental investigation of pressure grouting in sand. Soils and Foundations, (Accepted for publication) (2015)

6. A. Bezuijen, M.P.M. Sanders, D. Hamer, A.F. Tol, Laboratory tests on compensation grouting, the influence of grout bleeding. Proc. WTC, Prague (2007)

7. F. Tuncdemir, and U. Ergun, Proceedings of the Institution of Civil Engineers Ground Improvement , , May 2009 Issue GI2, 93-101(2009)

8. T.G. Santhosh Kumar, M.A. Benny, A.Sridharan, T.J. Babu, Bearing Capacity Improvement of Loose Sandy Foundation Soils through Grouting, International Journal of Engineering Research and Applications (IJERA) Vol. 1, Issue 3.1026-1033 (2011)

9. S. K. Vanapalli, D. G. Fredlund, D. E. Pufahl, A. W. Clifton, Model for the prediction of shear strength with respect to soil suction, Canadian Geotechnical Journal, 33(3): 379-392 (1996) 